$\xi=-1$

\title{
Development of reversed deep drawing without blank-holder for producing brass elliptical cup
}

\author{
Ali Hassan Saleh 1 *, Hani Aziz Ameen ${ }^{2}$, Ola Hussein Abed Al Radh ${ }^{3}$ \\ ${ }^{1}$ Middle Technical University-Institute of Technology-Baghdad, ${ }^{2}$. Tech. Eng. College/ Baghdad ${ }^{3}$, Tech. Eng. College/Baghdad. \\ *Corresponding author E-mail: Ali_aljibury1956@yahoo.com
}

\begin{abstract}
A new technique "Reverse Deep Drawing Process" without blank holder was adopted, for the single stage to produce an elliptical cup through an elliptical die. In this process an elliptical-cup is produced by pushing an elliptical blank using a hollow elliptical punch through an elliptical die in a single stroke. FEM via ANSYS is used to analyze this process. The clearance ratio was varied to study its effect on some parameters of this process like load, stress, strain, thickness distributions. A die with clearance $=1 \mathrm{~mm}$ and blank thickness $=1 \mathrm{~mm}$ gave the best drawability in this technique and no wrinkling observed on the product but it has minimum earring. Several attempted have been done to get the shape and dimensions of the blank, the major axis (a) $=85 \mathrm{~mm} \&$ the minor axis (b) $=65 \mathrm{~mm}$ was the better blank for this process to produce elliptical cup of major axis is twice minor axis. Good agreements are evident between the experimental and finite element results; the discrepancy is $4.0797 \%$ for load-extension and $0.852 \%$ for the wall thickness in minor axis and $1.145 \%$ in major axis.
\end{abstract}

Keywords: Reverse Deep Drawing; Elliptical Cup; Blank Holder; Clearance Ratio; ANSYS; Finite Element Method.

\section{Introduction}

In deep drawing process the blank holder is used to prevent wrinkling and to control the material flow into the die cavity. When a very high blank holder force is applied, the deep drawing process becomes a stretching process [1]. Deep drawing operation can be performed without blank holders. Some theories consider a thick stock- eligible for drawing without a blank holder; others judge the possibility of eliminating the blank holder by altering the geometry of the drawing die. Recently many researchers interested in deep drawing without a blank holder such as conical and tractrix dies for relatively thin sheet. Hassab-Allah, (1993) [2] produced circular cup using conical die without blank-holder. He concluded that the ratio of blank diameter to blank thickness $(d / t)<50$ gets sufficient to eliminate the need of blank-holder and prevents wrinkling and buckling. Hassab-Allah et al,(2006)[3] proposed a novel forming technique for drawing square cups in which a circular blank is drawn without a blank holder through a conical die. They used FEM to study this process and concluded that the high values of limiting drawing ratios (LDR`s) were obtained. They also concluded that the material flow between the straight walls and the corners of the deformed part was found to be improved. Hassab-Allah,(2006) [4] manufactured square cups by drawing circular blanks of relatively thin sheet metal through conical die without blank-holder. He concluded that the LDR improved with the proposed new technique. Dhaiban, et al, (2014) [5] produced elliptical cups without blank-holder or draw beads using a conical die. They built 3D parametric finite element model. They studied the effect of die, punch geometry, radius of punch fillet and length of die aperture on drawing load, limiting drawing ratio, and thickness strain of the cup. They obtained limiting drawing ratio of (2.28). Mohsen Hassan.et al,(2014) [6] used (FEA) to study the effect of geometric parameters on the ability of forming a cup with a square shape which producing without blank holder in order to find the optimum dimensions of the square punch and conical die. Cups of square shape were successfully produced with drawing ratio of 3.07 and 2.93 for brass and aluminum respectively. They found that the (LDR's) in this method is better than that obtained by using improved traditional methods include blank holder. Ravikant Patel.et al, (2014) [7] studied the optimum shape of blank for deep drawing of cylindrical cup without ears. They concluded that the use of optimal blank i.e. non circular blank produce considerable reduction in \% earring height, contact force hence improves the formability compared to initial blank. Ali and Ammer, (2015) [8] studied a technique of "Reverse Deep Drawing Process" without blank holder to produce a cylindrical cup through a conical die. FEM is used to analyze this process with commercially available software (DEFORM 2D V10). They obtained best results with die cone angle of $30^{\circ}$, clearance ratio of (0.9) and graphite grease lubricant gave the best drawability which required less drawing force with improvement of surface roughness. M.A. Hassan.et al,(2015) [9] obtained values of limiting drawing ratio (3.44 and 3.37) for brass and aluminum respectively relate star cup when they developed a new process to produce triangular, star, rose and clover cross-section cups. They found that these results and height cup are larger than that obtained by using conventional deep drawing process.

In the current study eliminating of blank-holder in reverse deep drawing process was adopted for producing elliptical cup from elliptical blank. Finite element analysis was used to investigate the effect of clearance ratio on the parameters of this process in addition to determine experimentally the optimal shape and dimensions of blank. 


\section{Finite element analysis}

The reverse deep drawing proposed that the elliptical cup can be drawn by pushing elliptical blank using elliptical hollow punch inside outer die have inner elliptical die in its elliptical hollow as shown in fig.(1).

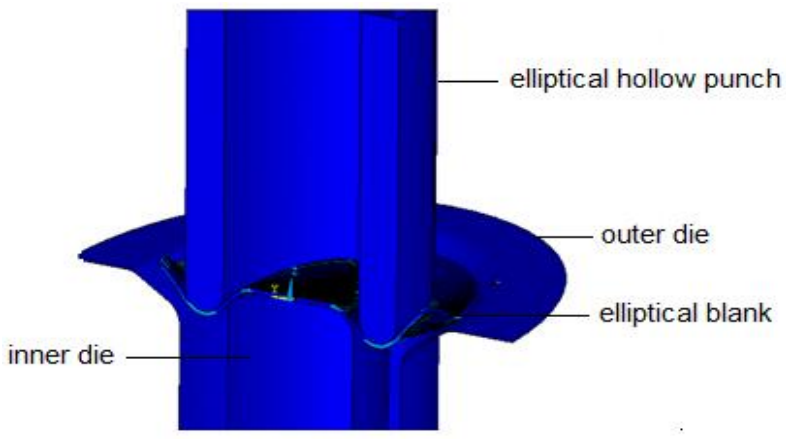

Fig. 1: Inverse Deep Drawing without Blank Holder.

ANSYS 15.0 software was used to simulate the process proposed in current study to produce elliptical cup with dimension of $(a=56 \mathrm{~mm}, b=28 \mathrm{~mm}$ and height $=23 \mathrm{~mm})$. Nonlinear problem was solved using "Newton-Raphson" implicit approach, while elastic behavior was considered as linear. Von Mises yield criterion was adopted to model the plastic response (isotropic) and Hill's 1948 yield criterion (anisotropic). SOLID 185 is used for the 3-D modeling of solid structures. TARGE170 is used to represent various 3 -D target surfaces for the associated contact elements (CONTA173 and CONTA174). . Elliptical model was adopted with variation in the inner die dimension to satisfy six clearance ratios $(\mathrm{c} / \mathrm{t}=1, \quad \mathrm{c}=\mathrm{t}=1, \quad \mathrm{t}=1), \quad(\mathrm{c} / \mathrm{t}=1, \quad \mathrm{c}=\mathrm{t}=0.9, \quad \mathrm{t}=0.9), \quad(\mathrm{c} / \mathrm{t}=1$, $\mathrm{c}=\mathrm{t}=0.8, \mathrm{t}=0.8),(\mathrm{c} / \mathrm{t}=1.111, \mathrm{c}=1, \mathrm{t}=0.9),(\mathrm{c} / \mathrm{t}=1.222, \mathrm{c}=1.1$, $\mathrm{t}=0.9),(\mathrm{c} / \mathrm{t}=1.25, \mathrm{c}=1, \mathrm{t}=0.8)$.Outer die have entrance taper of $30^{\circ}$ and fillet of all edges of hollow punch, inner die and outer die were taken as $(4 \mathrm{~mm})$ [10].Coefficient of friction was taken $(\mu=0.08)$ where silicon grease was used as a lubricant[10].Boundary condition was determined as symmetry of a quarter part with contact surface between punch and blank and between die and blank. Figure (2) illustrates the model of the elliptical reverse deep drawing without blank holder.
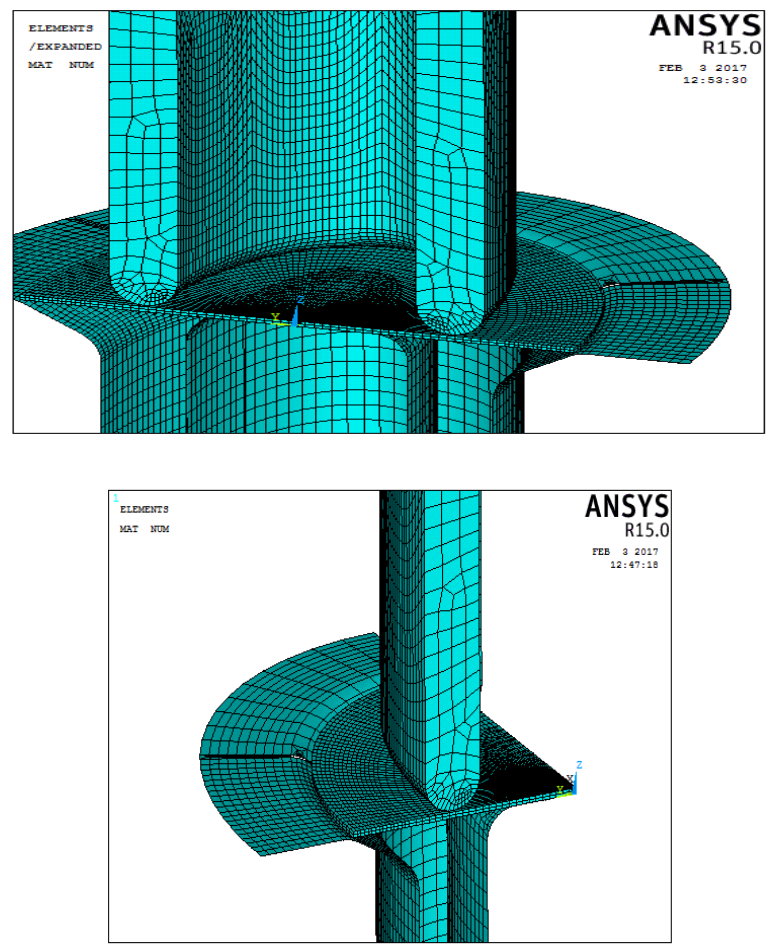

Fig. 2: Reverse Deep Drawing Model for Elliptical Cup.

\section{Experimental procedure}

Copper alloy $(\mathrm{CuZn37})$ is the major brass alloy for the cold forming process was used as blank of thickness $\left(t_{0}=1 \mathrm{~mm}\right)$ in this work. Annealing treatment was done on blank at $550^{\circ} \mathrm{C}$ for half hour and cooling in furnace.

\subsection{Material properties}

Table (1) shows the mechanical properties of blank material obtained through tensile test.

Table 1: Mechanical Properties of Brass $(\mathrm{Cu} \mathrm{Zn} 35)$

\begin{tabular}{llllll}
\hline \multirow{3}{*}{ Property } & $\begin{array}{l}\text { Yield } \\
\text { point } \\
(\mathrm{MPa})\end{array}$ & $\begin{array}{l}\text { Tensile } \\
\text { strength } \\
(\mathrm{MPa})\end{array}$ & $\begin{array}{l}\text { Young's } \\
\text { modulus, }\end{array}$ & $\begin{array}{l}\text { E (GPa) } \\
\text { Poisson's }\end{array}$ & Elongation $\%$ \\
\hline Nominal* $^{*}$ & $\leq 180$ & $300-370$ & 110 & 0.35 & $\geq 38$ \\
Actual** & 165 & 355.5 & 110 & 0.35 & 46.5 \\
\hline
\end{tabular}

*: Source ASM Handbook volume2, 2005.

**: Tested by (United Test) tension test device in Institute of Technology / Baghdad.

\subsection{Deep drawing tools}

Punch, inner die and outer die were designed and manufactured for producing elliptical cup with eliminating of blank holder, as shown in Fig (3). The tools are made from steel (CK45).

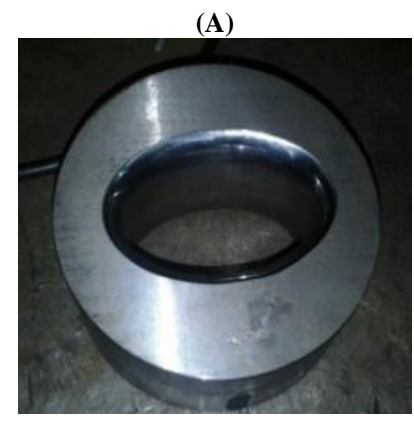

(C)

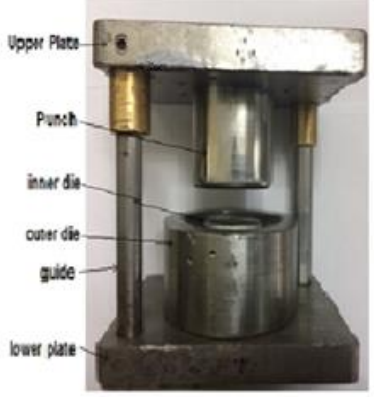

(B)

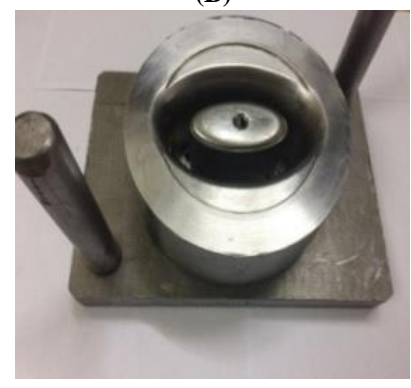

(D)

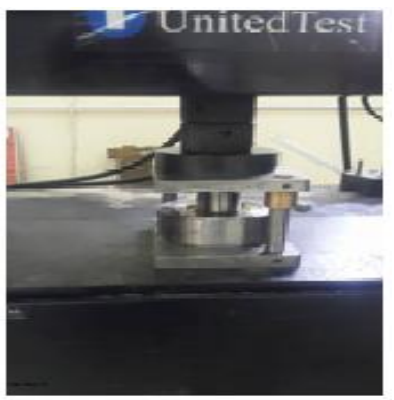

Fig. 3: A) Outer Die, B) Inner Die, C) Assembly Dies with Punch without Blank Holder, D) Deep Drawing Test.

\subsection{Preparation of blank}

Blank was prepared from sheet of copper-zinc alloy with thickness $(1 \mathrm{~mm})$,four sizes of blank are taken, firstly with circular shape of diameter $85 \mathrm{~mm}$, then elliptical shape had the size (the major axis (a) $=95 \mathrm{~mm}$, the minor axis $(\mathrm{b})=85 \mathrm{~mm})$, elliptical size with ( the major axis $(a)=85 \mathrm{~mm}$, the minor $\operatorname{axis}(b)=75 \mathrm{~mm})$, and finally elliptical size with (the major axis $(a)=85 \mathrm{~mm}$, the minor axis (b) $=65 \mathrm{~mm})$. The blanks are cut from sheet using wire cutting machine as an elliptical blank .The product elliptical size is (the major axis (a) $=56 \mathrm{~mm}$, the minor axis (b) $=28 \mathrm{~mm}$ ) and height 23 $\mathrm{mm}$ with thickneees (1)mm ,Fig. (4) Shows the size of blank and product. 

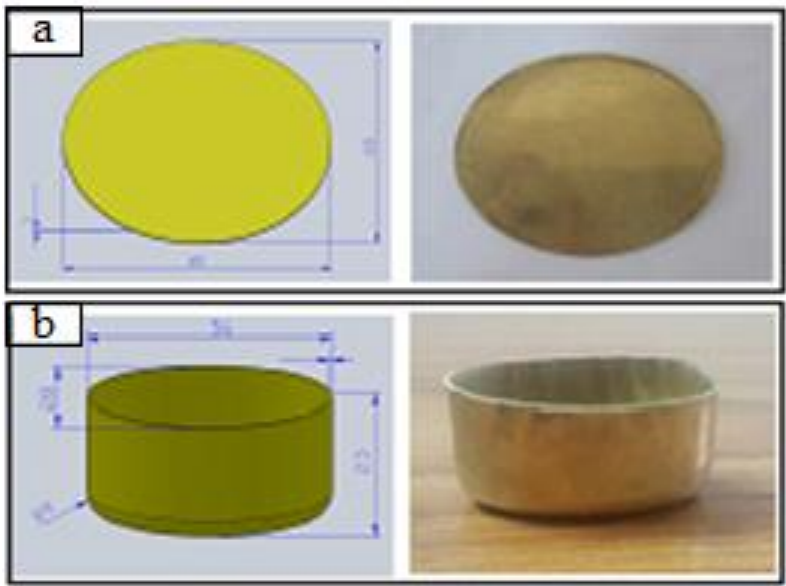

Fig. 4: (A) Blank Size, (B) Product.

\subsection{Strain measurement}

A pattern of grid with $2 \mathrm{~mm}$ square was printed on the elliptical blank to determine strain distribution on the cup during reverse deep drawing. Mechanical grid marker was used for this purpose as shown in fig. (5-a). Cup wall thickness was measured by divided drawn cup into two parts using wire cutting machine (fig. 5-b, 5-c). Digital thickness micrometer was used to determine the cup wall thickness, while the variations in the grid square during the forming is measured with aid of AutoCAD software.
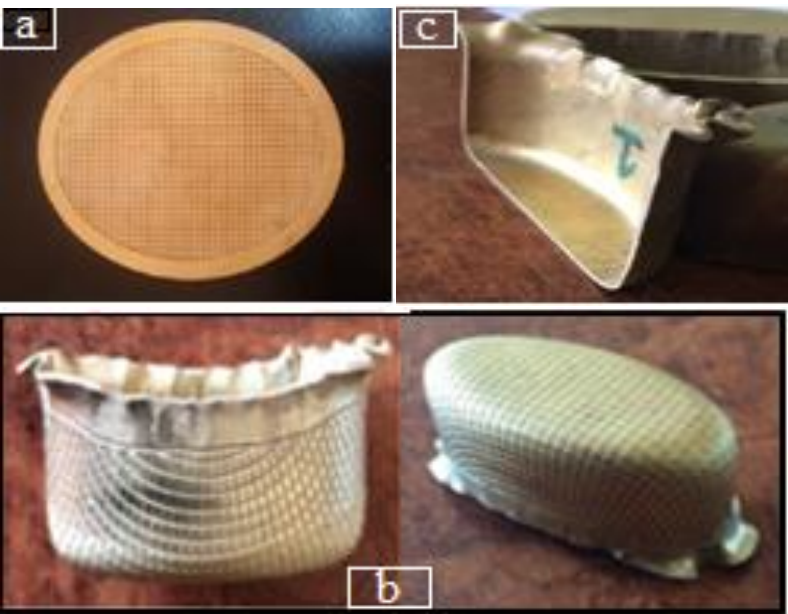

Fig. 5: A) Grid Of Blank, B) Distortion of Grid Square on the Cup, C) Sample of Divided Cup.

\section{Results and discussion}

\section{1. Blank size}

Several attempted have been done to get the optimum shape and dimensions of the blank to produce elliptical cup successfully in the proposed mechanism of reverse deep drawing without blankholder. The circular shape of blank was failed and the elliptical shape of blank with dimension of $(a=85 \mathrm{~mm}, b=65 \mathrm{~mm})$ was only successful. When elliptical cup with above dimension is produced using elliptical blank, the waist material after trimming the end of cup become minimum compare with the work done by Dhaiban [5] that the cup produced using conical die have high earring and result in largest waist of material.

\subsection{Effect of the clearance ratio $(\mathrm{c} / \mathrm{t})$}

The commercial software (ANSYS 15.0) was used for preprocessing. Three thicknesses of blanks were taken $(0.8,0.9$ and 1$)$ $\mathrm{mm}$, and clearance ratio $(\mathrm{c} / \mathrm{t})(1,1.111,1.2222,1.25)$. Fig. (6) illustrates that the thickness $(\mathrm{t}=1)$ and the clearance ratio $(\mathrm{c} / \mathrm{t}=1)$ gave the best draw ability in this mechanism of process than the others and considered as the optimum case to experimental test for comparison. It is obvious that all the curves have the same trend for different clearance ratio and the maximum drawing force taken for the clearance ratio $(\mathrm{c} / \mathrm{t}=1.25)$. The max. effective stress appeared with the case $(\mathrm{C}=1.1 \mathrm{~mm}, \mathrm{t}=0.9 \mathrm{~mm})$ as shown in fig.(7).

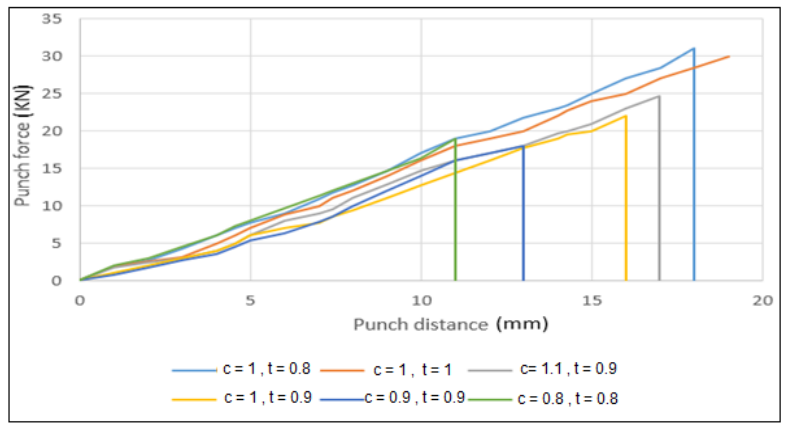

Fig. 6: Punch Force-Distance, for Elliptical Deep Drawing Process.
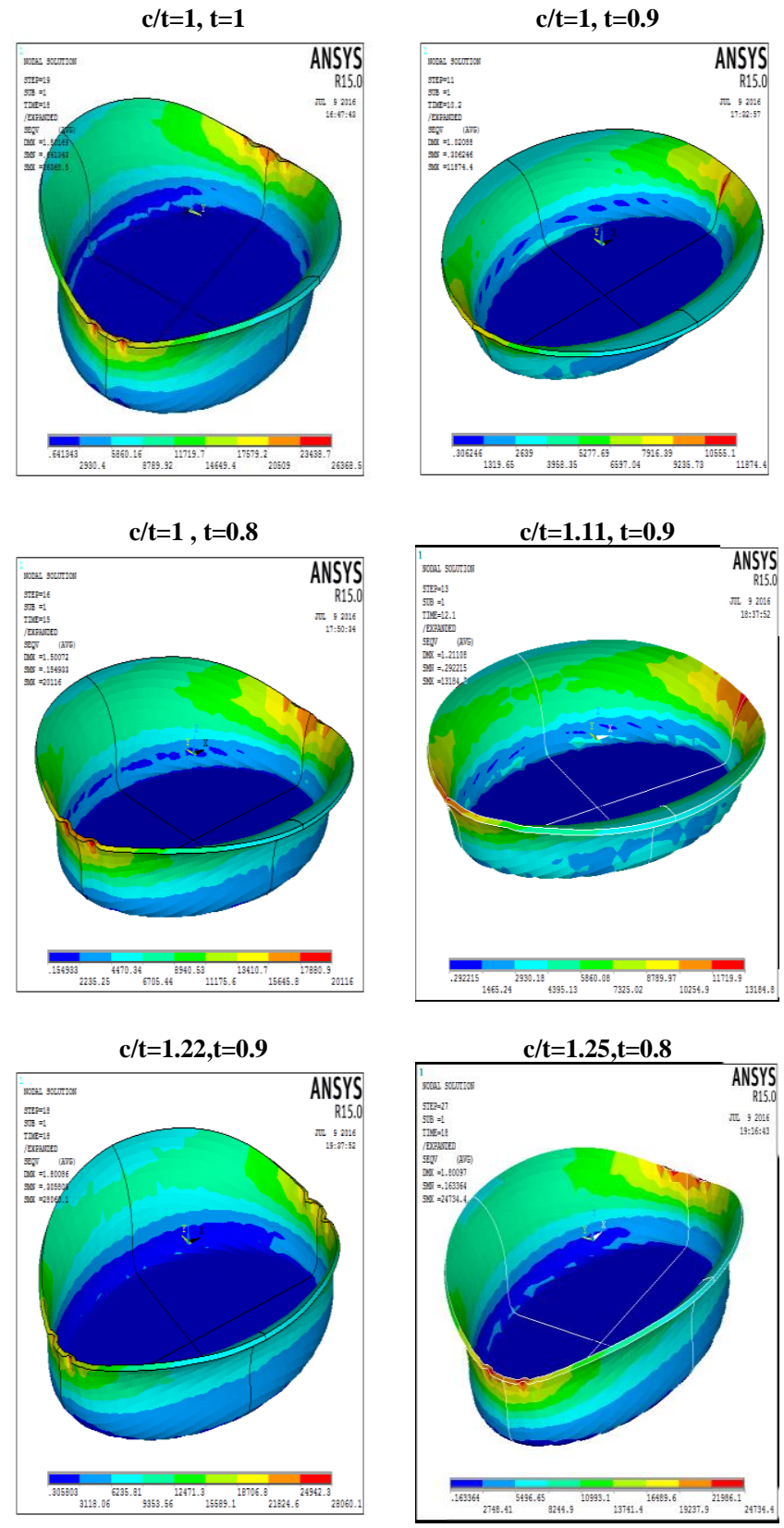

Fig. 7: Equivalent Stress Distribution for Different Clearance Ratio of Cases Studies. 


\subsection{Effect of punch velocity on the formability of ellipti- cal cup}

In order to investigate the effect of drawing speed on reverse deep drawing process proposed in this study, three speed are chosen $(3,6$ and 9$) \mathrm{mm} / \mathrm{min}$. Figure(8) illustrates the effect of drawing speed on drawing force experimentally. It is clear from this figure that at an increase in drawing speed from (3 to 6) $\mathrm{mm} / \mathrm{min}$ no effect on drawing force will occur, but when drawing at speed of (9) $\mathrm{mm} / \mathrm{min}$, it is noticed that the maximum drawing force will increase. The reason of this belongs to the increasing of strain hardening when drawing speed increases, and the stress will increases as a result and leads to increasing drawing force.
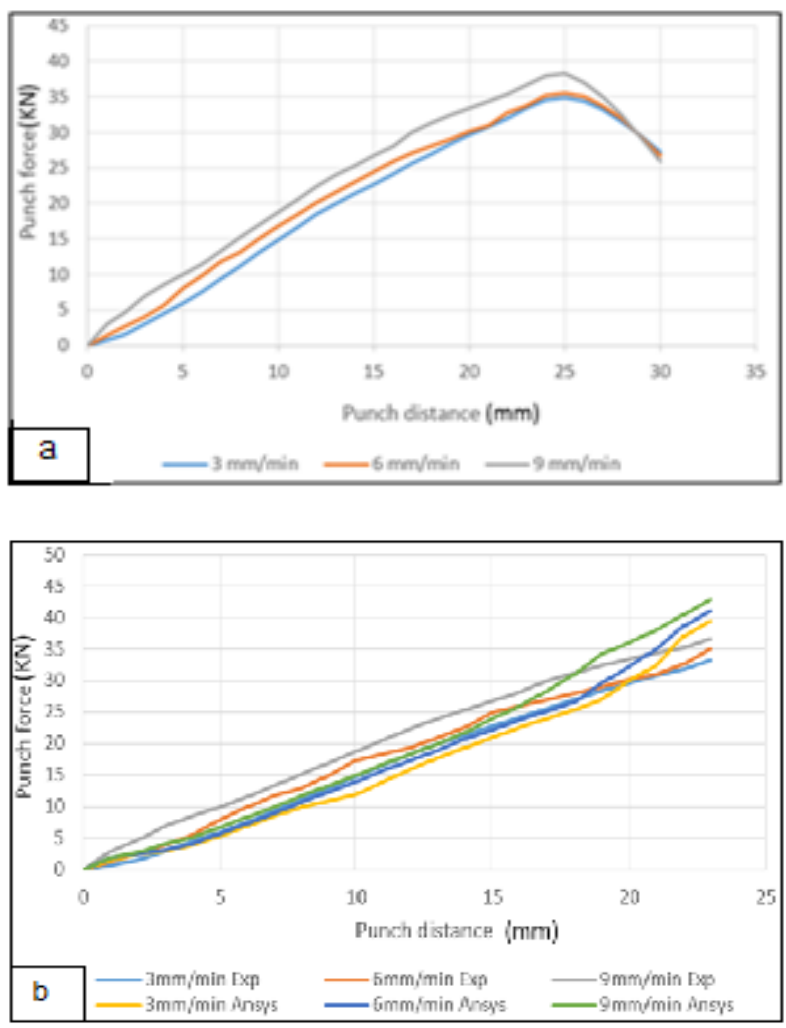

Fig. 8: The Effect of Drawing Speed on Drawing Force A) Experimentally B) Theoretically and Experimentally.

Figures (9) to (11) represent the effect of drawing speed on strain distribution over the cup wall. It is clear from the figures that the strain distribution of drawing speed at(3and 6)mm/min are similar in shape, and approximately have the same value. This is because of little difference between these speeds, thus the variation in the strain values is too small. But at drawing speed equal to (9) $\mathrm{mm} / \mathrm{min}$, it is noticed at the cup corner (necking point), the values of all strain are larger than the other two previous drawing speeds. This is due to the sever deformation in this area at high drawing speed while at the cup wall the values of strain have the same behavior and approximately the same values for the three drawing speeds.
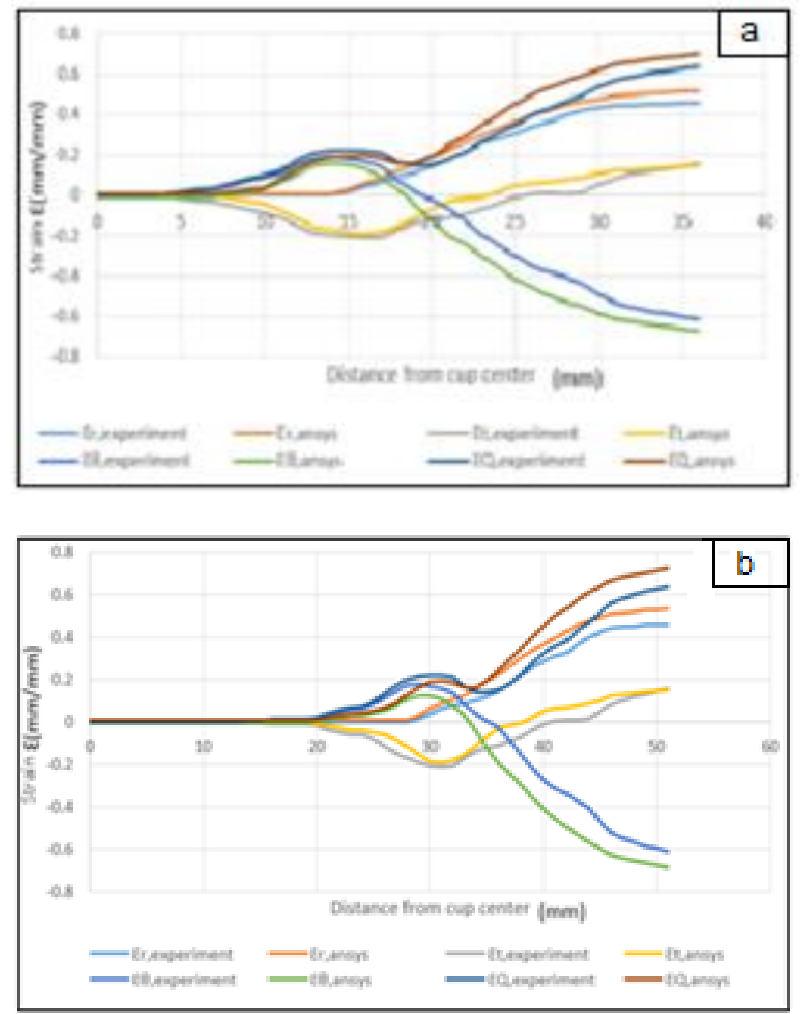

Fig. 9: Strain Distribution from Cup Center in A) Minor Axis, B) Major Axis for Punch Speed (3mm/Min) (Experimental and ANSYS).
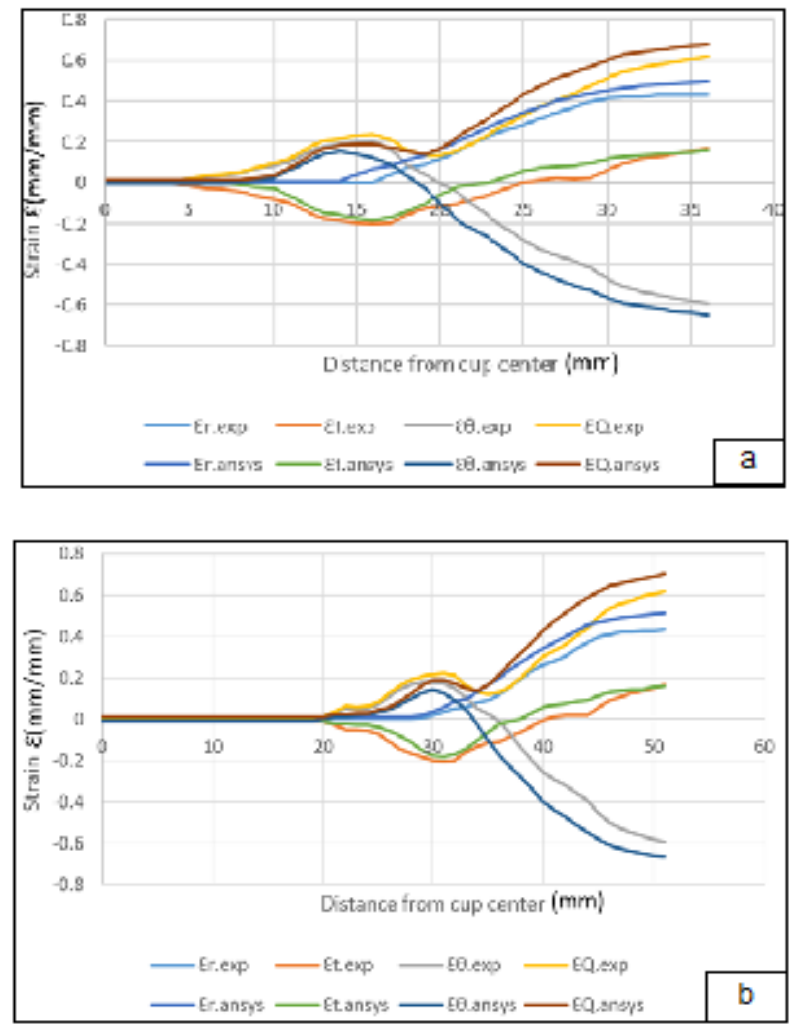

Fig. 10: Strain Distribution from Cup Center in A) Minor Axis, B) Major Axis for Punch Speed (6mm/Min) (Experimental and ANSYS). 

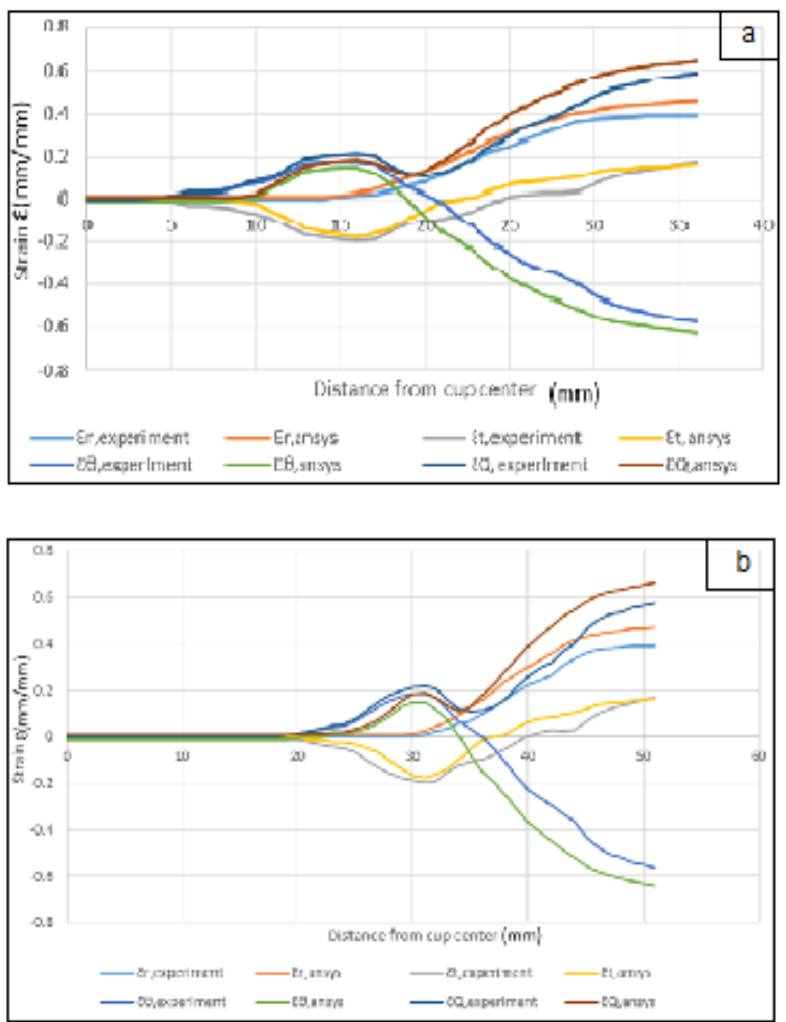

Fig. 11: Strain Distribution from Cup Center in A) Minor Axis, B) Major Axis for Punch Speed (9mm/Min) (Experimental and ANSYS).

\subsection{Wall thickness distribution}

Distribution of thickness wall on the product from cup center was found. It is observed that the thickness is constant under the punch base. Where no deformation occurs in this area due to friction which prevent any deformation of the metal under the punch. At the next zone, thinning will occur, due to an increase stretching exerted by the high tensile stress in this area, and then increases on the cup wall until it reaches a maximum value. The hoop stress (circumference) tends to thicken the blank in the end of the cup wall. Figure (12) illustrates the wall thickness distribution in the minor axis of elliptical cup (experimentally and by ANSYS software) for (3, 6 and $9 \mathrm{~mm} / \mathrm{min})$. Good agreement is evident between these results where the discrepancy was $0.852 \%$. Figure (13) illustrates the wall thickness distribution in the major axis of elliptical cup (experimentally and by ANSYS software) for (3, 6 and 9 $\mathrm{mm} / \mathrm{min}$ ). Good agreement is evident between these results where the discrepancy was $1.145 \%$.

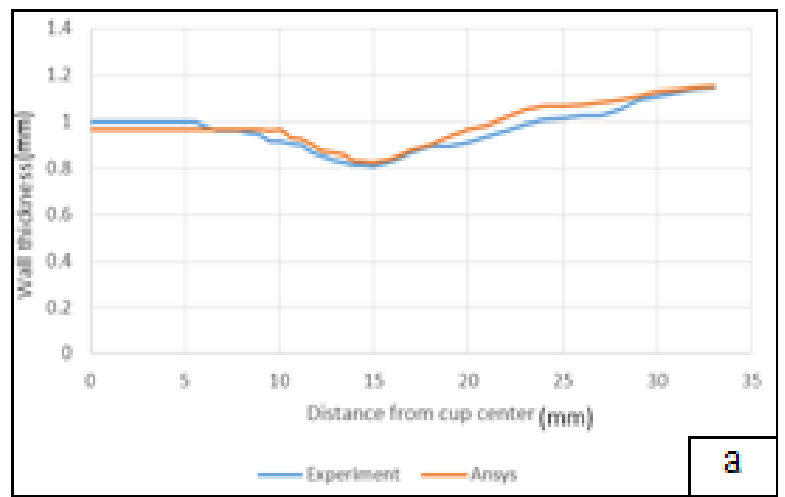

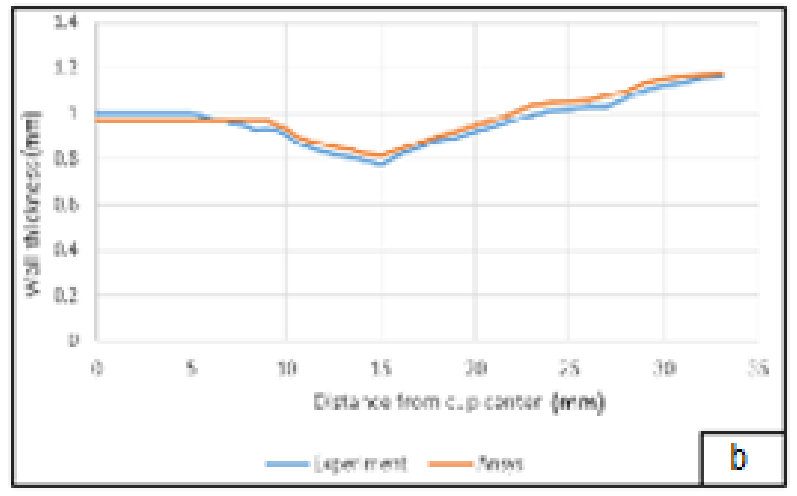

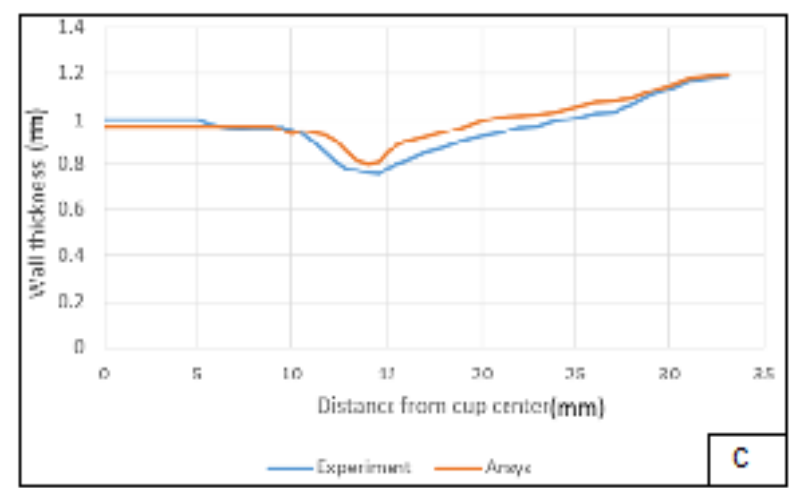

Fig. 12: Wall Thickness Distribution in the Minor Axis of Elliptical Cup at Punch Speed, (A) (3mm/Min), B) (6mm/Min), C) (9mm/Min).
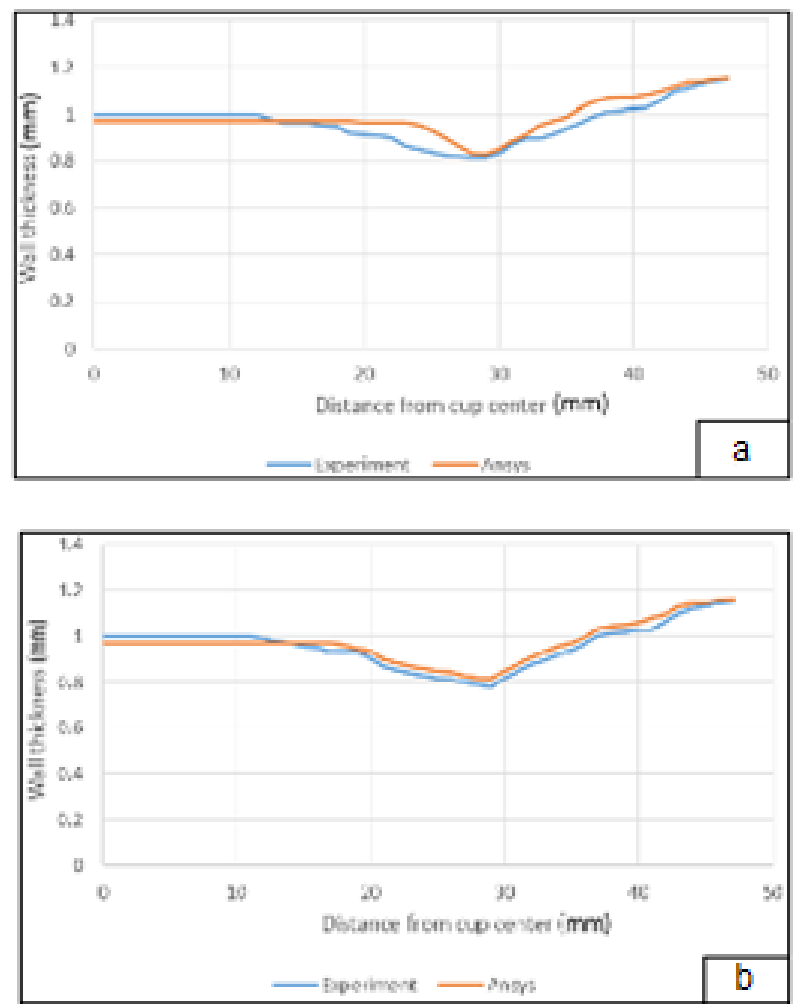


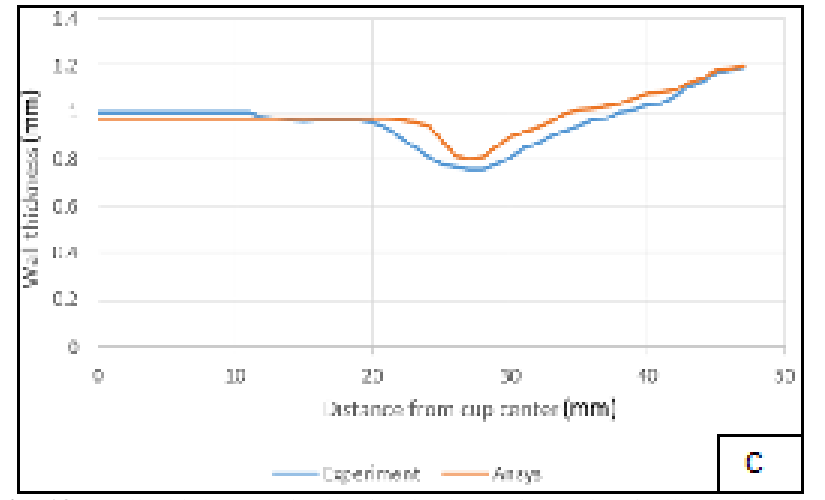

Fig. 13: Wall Thickness Distribution in the Major Axis of Elliptical Cup at Punch Speed, (A) (3mm/Min), B) (6mm/Min), C) (9mm/Min).

\section{Conclusions}

1) The present technique of reverse deep drawing process with eliminating blank holder to produce elliptical cup was gave sound product from thin plate.

2) The elliptical blank with dimensions of major axis $=85 \mathrm{~mm}$ and minor axis $=65 \mathrm{~mm}$ is the optimum blank size to produce cup of major axis $=56 \mathrm{~mm}$, minor axis $=28 \mathrm{~mm}$ and height $=23 \mathrm{~mm}$ with minimum earring and wrinkling at the end of cup.

3) Punch speed of $(6 \mathrm{~mm} / \mathrm{min})$ is the best to produce successful cup in this proposed process of reverse deep drawing.

4) Good agreement is evident between the experimental and finite element results; the discrepancy is $4.0797 \%$ for loadextension and $0.852 \%$ for the wall thickness in minor axis and $1.145 \%$ in major axis.

\section{References}

[1] W.K. Al-Samaraey."Studying the Effect of Die Geometry on Deep Drawing Operation Using Finite Element Method", (Ph,D)thesis , University of Technology , Department of Production Engineering and Metallurgy , (2003).

[2] I.M. Hasab-Alla," A Finite Element Simulation and Experimenta Verification of the Deep Drawing of Sheet Metals Without Blankholder With Simultaneous Corrective Ironing", Ph.D thesis, Assiut university, Egypt,(1993).

[3] I. M. Hassab-Allah, L. M. A. Hezam, and M. G. El-Sebaie,"A Novel Forming Technology For Drawing Square Cups" International Conference on Production Engineering \&Design For Development, PEDD7, Cairo, February 7 - 9,(2006).

[4] I. M. Hassab -Allah, "Finite Element Simulation of Square Cup Drawing Through a Conical Die " Fourth Assiut University Int. Conf. on Mech. Eng. Advanced Tech. For Indus. Prod., December 12-14 (2006).

[5] Abdullah A. Dhaiban, M.-Emad S. Soliman, M.G. El-Sebaie," Finite Element Modeling and Experimental Results of Brass Elliptic Cups Using a New Deep Drawing Process Through Conical Dies" Journal of Materials Processing Technology; 214, 4; 828-838, (2014). https://doi.org/10.1016/j.jmatprotec.2013.11.025

[6] Mohsen Hassan, LabibHezam, Mohamed El-Sebaie, JudhaPurbolaksono,"Deep Drawing Characteristics of Square Cups Through Conical Dies", The International Conference on Technology of Plasticity, ICTP 2014, 19-24 October (2014).

[7] Ravikant Patel, Manish Raj, AkshayKumar ," Finite Element Simulation for Determining the Optimum Blank Shape for Deep Drawing Process ", Int. Journal of Engineering Research and Applications , Vol. 4, Issue 11(Version - 5), pp.94-100, November (2014).

[8] Ali Hassan Saleh ,Ammer Khalaf Ali, "Development Technique for Deep Drawing Without Blank Holder to Produce Circular Cup of Brass Alloy", International Journal of Engineering \& Technology, 4 (1) 187-195,(2015) https://doi.org/10.14419/ijet.v4i1.3516.

[9] M.A. Hassan, I. M. Hassab-Allah, L. M. A. Hezam, N. A. Mardi, M. Hamdi ,"Deep Drawing of Asymmetric Cups Through Conical Die without Blank Holder ",Proceedings of the World Congress on Engineering, Vol II ,WCE, July 1 - 3,( 2015).

[10] Ammer Khalaf Ali, "Effect of Some Geometrical and Operational Parameters of Reversed Drawing Process, Without Blank Holder, on the Stress Distribution ", M.Sc. thesis, Engineering Technical College-Baghdad, (2014). 